Address for Correspondence: Dr. Massimo Vincenzi, Unit of Gastroenterology and Digestive Endoscopy, San Pier Damiano Hospital, Faenza, RA, Italy.

Email: massimovincenzi@hotmail.com

\begin{tabular}{|l|}
\hline Access this article online \\
\hline $\begin{array}{l}\text { Website: } \\
\text { www.intern-med.com }\end{array}$ \\
\hline DOI: \\
10.1515/jtim-2017-0004 \\
\hline Quick Response Code: \\
\hline \\
\\
\\
\\
口) \\
\hline
\end{tabular}

\title{
Effects of a low FODMAP diet and specific carbohydrate diet on symptoms and nutritional adequacy of patients with irritable bowel syndrome: Preliminary results of a single-blinded randomized trial
}

\author{
Massimo Vincenzi ${ }^{1}$, Irene Del Ciondolo ${ }^{2}$, Elisa Pasquini ${ }^{2}$, \\ Katia Gennai ${ }^{2}$, Barbara Paolini ${ }^{2}$
}

'Unit of Gastroenterology and Digestive Endoscopy, San Pier Damiano Hospital, Faenza, RA, Italy; ${ }^{2}$ Dietetics and Clinical Nutrition Unit, Azienda Ospedaliera Universitaria Senese, Policlinico Santa Maria alle Scotte, Siena, Italy

\section{ABSTRACT}

Background and Objectives: IBS is the most common functional disease of the low gastrointestinal tract. Recently, the interest towards a diet approach has increased, for example, a diet with low content of fermentable oligosaccharides, disaccharides, monosaccharides and polyols (FODMAPs). The aim of the present study is to evaluate the efficacy of a low FODMAP diet and a specific carbohydrate diet (SCD) conducted for 3 months on symptoms and to evaluate the deficiencies of vitamin $D$ and folic acid in patients affected by IBS, matching the Rome IV criteria. Methods: We evaluated 73 patients divided into 2 groups: one submitted to low FODMAP diet and one to SCD, for 3 months. Patients were assigned to one of the 2 groups randomly and blinded. All the patients filled a visual analogue scale (VAS) to evaluate the severity of symptoms and a diary to evaluate the number of days with symptoms, and this was repeated after 3 months. Final evaluation was made by a blinded investigator. Results: In the end, the patients with low FODMAP diet had a significant improvement in bloating and distension $(P=0.000)$; the group with SCD instead had a low but not a significant improvement. One way ANOVA showed comparable severity of symptoms in the 2 groups pre-diet $(P=$ $0.215)$, but a difference in the same symptoms after 12 days $(P=0.000)$. Tukey test showed a significant improvement in the low FODMAP diet group and only a trend of improvement in the second group of SCD. The vitamin D mean value in both groups at the time of enrollment was $38 \mathrm{ng} / \mathrm{mL}$; in the end, the mean value in the low FODMAP diet group was $32 \mathrm{ng} / \mathrm{mL}$ and in the SCD group was $22 \mathrm{ng} / \mathrm{mL}$, with a statistically significant difference. The folic acid mean value at the time of enrollment was $18 \mathrm{mg} / \mathrm{dL}$; in the end, the mean value in the low FODMAP diet group was $15 \mathrm{mg} / \mathrm{dL}$ and in the SCD group was $8 \mathrm{mg} / \mathrm{dL}$, with a statistically significant difference. Conclusion: Patients affected by IBS seem to have benefitted from a low FODMAP diet but not from an SCD, and a low FODMAP diet doesn't seem to cause vitamin $\mathrm{D}$ and folic acid deficiencies.

Key words: FODMAP, irritable bowel syndrome, diet, specific carbohydrate diet, bloating

\section{INTRODUCTION}

Irritable bowel syndrome (IBS) is a chronic functional gastrointestinal disorder with a pathophysiology only partially understood. It is characterized by abdominal discomfort or pain in combination with altered bowel habit, without any pathological abnormality of the gut wall..$^{[1]}$

Abdominal pain and bloating are the main symptoms of IBS and they often improve after evacuation. Abdominal pain is associated with altered bowel habit, ranging 
from diarrhea to constipation. Symptoms can modify over time, sometimes they can be very severe, sometimes they can disappear completely. ${ }^{[2]}$

Pathophysiology is not completely known, it is probably linked to abnormal GI motility, altered brain-gut communication, visceral hypersensitivity, low-grade inflammation and also, psychosocial factors can contribute to it. ${ }^{[3]}$ As a consequence of poor understanding of factors underlying the symptoms of IBS, only a few effective treatment alternatives are actually available, but new therapeutic approaches are ongoing. ${ }^{[4-5]}$

Many patients often refer to symptoms worsening after the consumption of certain foods, ${ }^{[6]}$ so they try different exclusion diets. Recently, many different dietetic approaches have been tried for IBS treatment, but there are only few clinical trials. ${ }^{[7-10]}$ Different exclusion diets or diets with low content of fat have been tried with controversial and inconsistent results. ${ }^{[11,12]} \mathrm{A}$ diet with increasing evidence of efficacy for the management of IBS is the low fermentable oligosaccharides, disaccharides, monosaccharides and polyols (FODMAP) diet. ${ }^{[13-15]}$ FODMAPs can pass unabsorbed to the colon, where they increase the luminal water through osmotic activity and induce gas production $(\mathrm{H} 2, \mathrm{CH} 4)$ due to fermentation by colonic bacteria, and lead to luminal distension and GI symptoms in susceptible individuals. ${ }^{[16-19]}$

Another approach is the Specific Carbohydrate Diet (SCD) proposed by the Gastroenterologist Sidney Hass in 1951. The diet allows carbohydrate foods consisting of monosaccharides only, and excludes disaccharides and most polysaccharides (such as linear or branch-chained multiple sugars or starches). The diet is supplemented with homemade yogurt fermented for 24 hours to minimize lactose, a disaccharide that is not allowed in the SCD. ${ }^{[20-23]}$ The SCD allows almost all fruits, vegetables containing more amylose (a linear-chain polysaccharide) than amylopectin (a branch-chained polysaccharide), nuts, nut-derived flours, dry-curd cottage cheese, meat, eggs, butter and oils. It excludes sucrose, maltose, isomaltose, lactose, grain-derived flours and all true and pseudograins, potatoes, okra, corn, fluid milk, soy, cheeses containing high amounts of lactose, as well as most food additives and preservatives. ${ }^{[24,25]}$

Gottschall hypothesized that patients with IBD can only optimally absorb the monosaccharide glucose, galactose and fructose due to a dysfunction of the host's disaccharidases that are necessary for the digestion and absorption of disaccharides and high amylopectin foodstuffs. ${ }^{[24]}$ This dysfunction is posited to arise from excessive mucus production, preventing the brush border intestinal enzymes from making contact with the disaccharidases and amylopectin, causing maldigestion and alteration of the microbiota.

SCD diet reduces the inflammation and dysfunction of microbiota and it should be beneficial in IBS patients. ${ }^{[25]}$

IBS patients are also at risk to develop nutritional deficiencies because of the frequent exclusion of some kinds of foods that can trigger or worsen their symptoms. The more frequent nutritional deficiencies are: iron, calcium, vitamin B12, folic acid, zinc, magnesium, vitamin $\mathrm{D}$ and $\mathrm{A} \cdot{ }^{[26,27]}$

\section{SUBJECTS AND METHODS}

The primary objective of the present study was to assess the efficacy of a low FODMAP diet on IBS symptoms as compared to a specific carbohydrate diet in outpatients with IBS.

A secondary objective was to evaluate the nutritional adequacy of the two diets, and changes in vitamin $\mathrm{D}$ and folic acid serum concentration with intervention. In this study (clinical single-blinded randomized trial), we recruited a group of adult patients meeting Rome IV criteria for IBS (Table 1), aged between 18 and 65 years, from the outpatient clinic UOSA Clinical Nutrition Unit of the Hospital in Siena (Azienda Ospedaliera Senese) and the outpatient Unit of Gastroenterology and Digestive Endoscopy of San Pier Damiano Hospital Faenza.

\section{Table 1: Rome IV Criteria}

\section{Rome IV Criteria}

Recurrent abdominal pain, on average, at least 1 day per week in the last 3 months, associated with 2 or more of following criteria*:

1. Related to defecation

2. Associated with a change in frequency of stool

3. Associated with change in form (appearance) of stool

* Criteria fulfilled for the last 3 months with symptom onset at least 6 months before diagnosis

Exclusion criteria were the presence of a severe cardiac, liver, neurologic, or psychiatric disease or a GI disease other than IBS (Crohn, diverticular disease, etc.) that could explain the current symptoms.

Coeliac disease was excluded by anti-transglutaminase antibodies and duodenal biopsies.

The use of probiotic products was allowed, but patients who consumed probiotic products were instructed to continue with an unaltered intake during the study period. Other medications were allowed, provided that they used 
them on a regular basis and were on a stable dose for at least 3 months before inclusion.

All patients were given study-specific verbal and written information before they gave their written consent to participate in the study.

\section{Screening}

In the first visit, the patients received verbal and written information about the study and gave informed consent. Patients were informed that the aim was to compare the two different diets with potential benefits for patients by alleviation of IBS symptoms (Table 2).

\section{Table 2: Screening of the patients}

\section{Screening at the first evaluation}

Dietetic evaluation with measurement of weight, height and BMI

Nutritional and clinical history

Blood test

Visual analogue scale

BMI, body mass index.

All the patients were submitted to a first dietetic evaluation with the measurement of weight, height and the calculation of BMI. Clinical history and nutritional history of the patients were recorded, along with the presence of IBS symptoms and eventual altered bowel habits.

We evaluated the blood levels of vitamin D and folic acid at the first visit and at the end of the observational period.

We evaluated the presence of inclusion and exclusion criteria.

All the patients filled out a visual analogue scale (VAS) from 0 (no or mild bloating) to 10 (severe bloating) to evaluate the severity of symptoms and VAS was repeated every 30 days.

The symptoms evaluated as per the validation questionnaire IBS-SSS (Irritable Bowel Syndrome, Severity Score System) were: abdominal pain intensity, abdominal pain frequency, abdominal distension, dissatisfaction with bowel habits, influence of IBS on life in general ("life interference") and alterations in stool consistency.

\section{Randomization}

After the enrollment, all the patients filled out a diary for 15 days to evaluate the number of days with symptoms and another diary for the complete observation period. Then, the participants were randomized to follow one of the two different diets (Group A: low FODMAP diet and Group B: Specific Carbohydrate diet SCD).

The analysis was performed using Statistica 12. The patients were, as per the instructions by a dietitian, advised to eat a low-FODMAP $\operatorname{diet}(\operatorname{diet} \mathrm{A})$ or to eat according to SCD $\operatorname{diet}(\operatorname{diet} \mathrm{B}$ ), and to follow these diets during the coming 3 months. All the patients were given a manual with specific instructions related to the diet and the substitution of different foods. (Table 3 and 4)

\section{Follow-up}

The patients were evaluated every 30 days with the repetition of dietetic evaluation. We evaluated the compliance to diet with the compilation of a food diary, compilation of VAS scale and eventual side effects. The final evaluation was made by a blind investigator. At the end of the observational period ( 3 months), we measured the

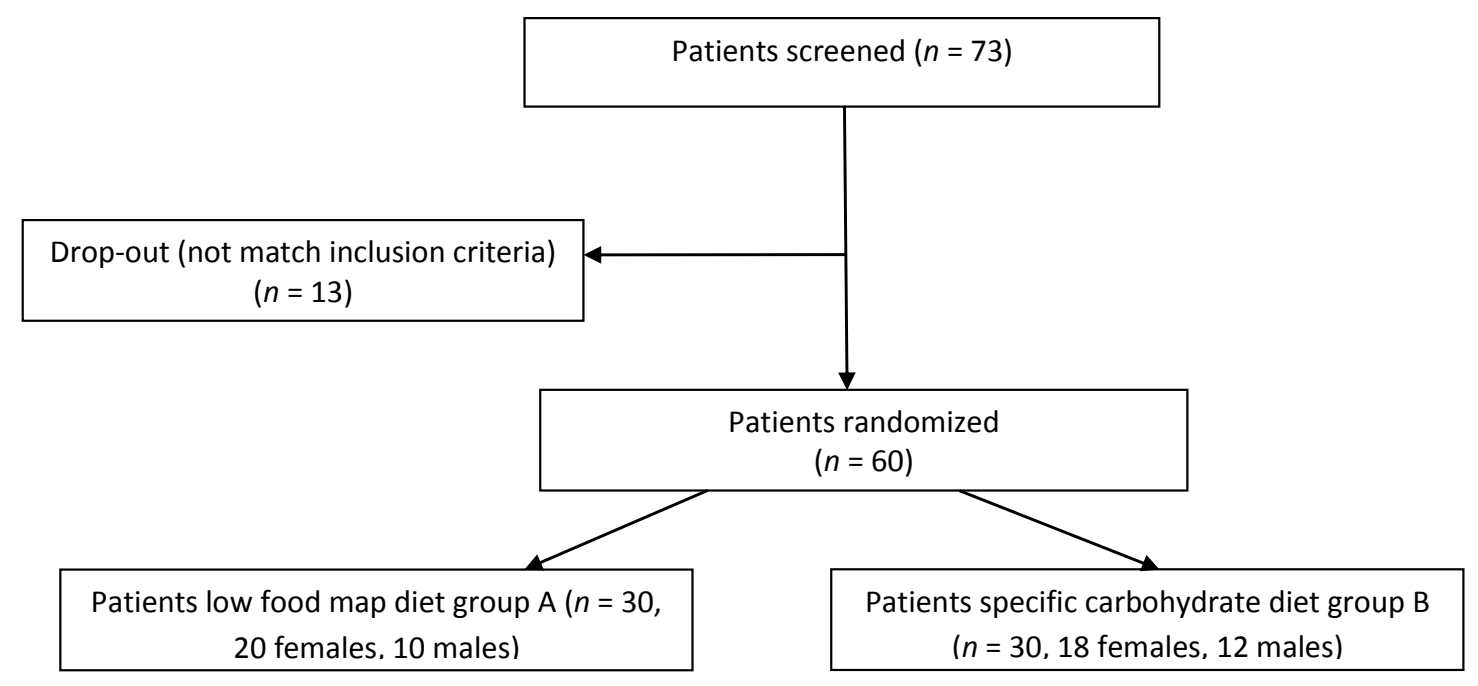

Figure 1: Flow chart of the first screening of patients for the study. 
Vincenzi et al: : Low FODMAP diet and specific carbohydrate diet on symptoms and nutritional adequacy in IBS patients

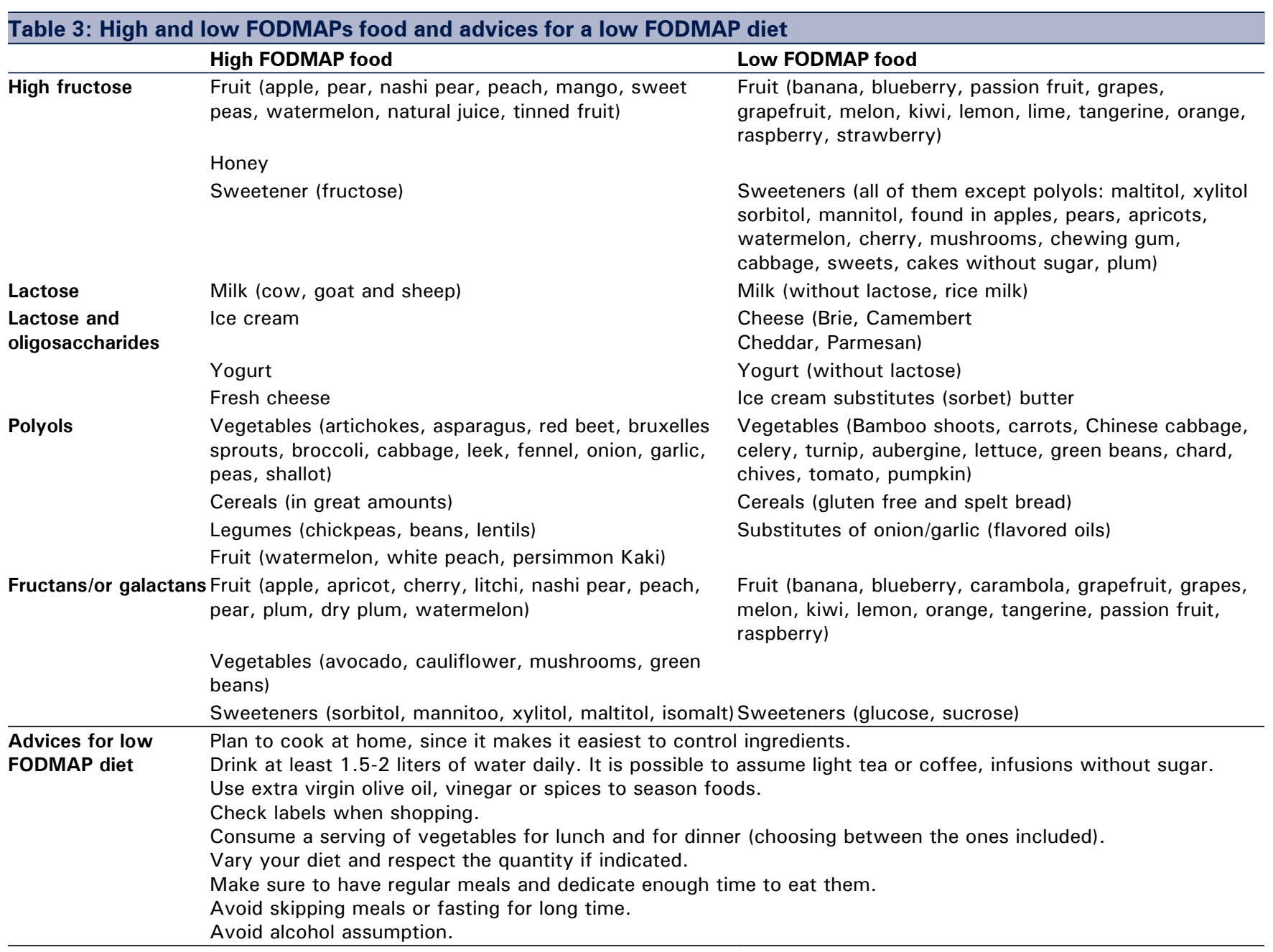

\begin{tabular}{|c|c|c|}
\hline & Food included in SCD diet & Food not included in SCD diet \\
\hline Meat, fish & Chicken, eggs, turkey, meat, fish, pork, game, lamb) & $\begin{array}{l}\text { Ham, sausage, hot dog, wurstel, processed meats in } \\
\text { general }\end{array}$ \\
\hline Vegetables & $\begin{array}{l}\text { All kind of fresh vegetables (Asparagus, broccoli, } \\
\text { cabbage, cauliflower, onion, garlic, carrots, mushrooms, } \\
\text { celery, pepper, fennel, pumpkin, aubergine, salad, } \\
\text { lettuce ...) }\end{array}$ & Canned veggies with added sugar or ingredients \\
\hline Fruit & $\begin{array}{l}\text { All kind of fresh fruit (apple, banana, kiwi, orange, pear, } \\
\text { tangerine ...) }\end{array}$ & Canned fruits with added sugar or ingredients, juices \\
\hline Dairy & Homemade prebiotic yogurt, goat cheese & Most dairy (milk, most yogurt, cheeses, ice cream ...) \\
\hline Legumes & Beans, lentils, peas & Soy chickpea, broad bean \\
\hline Spices & All of them & \\
\hline Cereals & 1 & $\begin{array}{l}\text { Wheat, barley, oats, rye, rice, soy, spelt, amaranth, } \\
\text { bulgur, quinoa and products made with grain flours }\end{array}$ \\
\hline Sweeteners & Honey & Sugar and other sweeteners \\
\hline $\begin{array}{l}\text { Advices for SCD } \\
\text { diet }\end{array}$ & $\begin{array}{l}\text { Plan to cook at home, since it makes it easiest to control } \\
\text { Drink at least } 1.5-2 \text { liters of water daily. It is possible to } \\
\text { Use extra virgin olive oil, vinegar or spices to season fooc } \\
\text { Check labels when shopping. } \\
\text { Vary your diet and respect the quantity if indicated. } \\
\text { Make sure to have regular meals and dedicate enough tim } \\
\text { Avoid skipping meals or fasting for long fasting. } \\
\text { Avoid alcohol assumption. } \\
\text { In place of grain flours, use things like almond or coconut } \\
\text { Avoid all legumes and reintroduce them gradually (soakec } \\
\text { Prepare your yogurt at home, fermented at least } 24 \text { hours }\end{array}$ & $\begin{array}{l}\text { ingredients. } \\
\text { assume light tea or coffee, infusions without sugar. } \\
\text { ds. } \\
\text { me to eat them. } \\
\text { it flours. } \\
\text { d and sprouted first). }\end{array}$ \\
\hline
\end{tabular}


blood values of vitamin $\mathrm{D}$ and folic acid in the 2 groups.

\section{Statistical analysis}

The baseline socio-demographic and clinical characteristics of the 2 groups were compared with t-test for continuous variables and chi squared test for categorical variables, and these characteristics did not differ between the 2 groups.

The continuous variables were compared with $t$-test, and the categorical variables with chi squared test. The intragroup differences of IBS symptoms, evaluated before and after the intervention, were assessed with paired t-test, inter groups differences with one way ANOVA with post hoc Tukey multiple comparison test.

\section{RESULTS}

A total of 73 patients were screened, including 42 females and 31 males; 13 did not meet the inclusion criteria. Sixty patients consecutively enrolled were randomized in 2 groups, one submitted to low FODMAPs diet and one to specific carbohydrate diet for 3 months.

We randomized 60 patients (38 females, 22 males, aged between 22 and 63 years) and they were divided into 2 groups of 30 patients each, group A followed a low FODMAP diet and group B followed an SCD diet for 3 months. Baseline socio-demographic and clinical characteristics of the 2 groups did not differ significantly (Table 5).

During the 3 months of observation there weren't any adverse effects and all the patients completed all the follow- ups. At $\mathrm{t} 0$, the intake of nutrients and of FODMAPs was similar in the 2 groups.

During the observational period, we obviously had a great change in the dietary habits of the participants. In group A, we had a great reduction of the intake of all kinds of FODMAPs, and a reduction in the carbohydrate and fiber intake as well; this result was less evident in group B. We didn't have any relevant variations on fat and protein intake in the 2 groups (Table 6).

All patients showed a good compliance to the dietetic therapy and consumed 5 meals per day for almost the complete observational period. Some patients (3 from group A and 11 from group B) complained about the monotony of diet and about the lack of some kinds of foods like soft cheeses and some types of fruit.

At the end of the observational period, the patients with low FODMAP diet had a significant improvement in bloating and distension $(P=0.000)$; the group with specific carbohydrate diet instead had a low but not statistically significant improvement.

In males of group $A$, we had a statistically significant reduction of BMI $(P=0.001)$; in women of group A we had a slight but not statistically significant weight reduction. Mean BMI at $\mathrm{t} 3$ in males of Group A was 25.1 $\mathrm{kg} / \mathrm{m}^{2}$ (SD 2.8), in females of group A was $24.9 \mathrm{~kg} / \mathrm{m}^{2}$ (SD 3.7); mean BMI at $\mathrm{t} 3$ in males of Group B was 29.2 $\mathrm{kg} / \mathrm{m}^{2}$ (SD 3.8), in females of group B was $24.8 \mathrm{~kg} / \mathrm{m}^{2}$ (SD 3.5). (Table 7)

Table 5: Characteristics of the 2 groups at T0

\begin{tabular}{lllll}
\hline & Group A & \multicolumn{3}{l}{ Group B } \\
\cline { 2 - 5 } & Female $(n=\mathbf{2 0})$ & Male $(n=10)$ & Female $(n=18)$ & Male $(n=12)$ \\
\hline Mean age (years) & $35 \pm 7.2$ & $37 \pm 8.3$ & $41 \pm 10.2$ & $41 \pm 6.32$ \\
Mean BMI $\left(\mathrm{kg} / \mathrm{m}^{2}\right)$ & $26.2 \pm 4.1$ & $28.2 \pm 5.2$ & $25.1 \pm 2.9$ & $29.1 \pm 4.2$ \\
Mean weight $(\mathrm{kg})$ & $68.7 \pm 10.1$ & $75.4 \pm 8.3$ & $65.6 \pm 7.3$ & $80.3 \pm 9.1$ \\
\hline
\end{tabular}

\begin{tabular}{|c|c|c|c|c|c|}
\hline \multicolumn{4}{|c|}{ Group A (low FODMAP diet) } & \multicolumn{2}{|c|}{ Group B (specific carbohydrate diet) } \\
\hline & TO $(n=30)$ & 3 months $(n=30)$ & $P$ value & TO $(n=30)$ & 3 months $(n=30)$ \\
\hline Energy (kcal) & $2150 \pm 432$ & $1769 \pm 320$ & $<0.001$ & $2245 \pm 270$ & $1828 \pm 254$ \\
\hline Protein $(g)$ & $89.2 \pm 34.8$ & $84.2 \pm 15,8$ & & $85.4 \pm 25.8$ & $72.0 \pm 34.2$ \\
\hline Fat $(g)$ & $86.5 \pm 19.6$ & $65.3 \pm 22.1$ & & $89.3 \pm 18.5$ & $76.3 \pm 22.5$ \\
\hline Carbohydrates $(\mathrm{g})$ & $210.7 \pm 34.9$ & $154.9 \pm 31.7$ & $<0.001$ & $215.0 \pm 32.8$ & $178.1 \pm 30.2$ \\
\hline Fiber $(g)$ & $20.1 \pm 3.8$ & $14.2 \pm 2.8$ & & $22.7 \pm 10.1$ & $18.9 \pm 3.4$ \\
\hline Total FODMAPs & $17.6 \pm 9.6$ & $2.5 \pm 1.2$ & $<0.001$ & $18.3 \pm 3.4$ & $14.1 \pm 10.2$ \\
\hline
\end{tabular}


One way ANOVA showed comparable severity of symptoms in the 2 groups pre-diet $(P=0.215)$, but a difference in the same symptoms after 12 days $(P=0.000)$. Tukey test showed a significant improvement in the low FODMAP diet group and only a trend of improvement in the second group following the specific carbohydrate diet. Vitamin D mean value in both groups at the time of enrollment was $38 \mathrm{ng} / \mathrm{mL}$; at the end of the diet therapy, the mean value of vitamin $\mathrm{D}$ in the low FODMAP diet group was $32 \mathrm{ng} / \mathrm{mL}$, and in the specific carbohydrate group was $22 \mathrm{ng} / \mathrm{mL}$ with a statistically significant difference; folic acid mean value at the time of enrollment was $18 \mathrm{mg} / \mathrm{dL}$; at the end of the observation, the mean value in the low FODMAP diet group was $15 \mathrm{mg} / \mathrm{dL}$ and in the specific carbohydrate diet group was $8 \mathrm{mg} / \mathrm{dL}$ with a statistically significant difference.

\section{DISCUSSIONS}

Fiber supplementation remains a critical approach in IBS treatment; however, its optimal application can be quite vague. A recent systematic review and a meta-analysis identified 12 trials that compared the effect of fiber supplementation with controls and they noticed only a marginal difference in the symptoms between the 2 groups. ${ }^{[28]}$

Subgroups analysis suggested that the benefit on IBS symptoms was limited to soluble fiber (psyllium/ispaghula husk) and not to the insoluble fiber (bran). Some kinds of fiber like bran can worsen some symptoms like abdominal pain or meteorism. ${ }^{[29]}$

The low FODMAP diet is associated with low intestinal fermentation and a significant improvement on symptoms in IBS patients. ${ }^{[30]}$ Austin reported an improvement on IBS-D with a very low carbohydrate diet (VLCD). ${ }^{[31]}$ Our data, accordingly with the recent literature confirm that patients affected by IBS seem to benefit from a low FODMAP diet but not from a specific carbohydrate diet; in addition to this, the low FODMAP diet doesn't seem to cause vitamin $\mathrm{D}$ and folic acid deficiencies with respect to the specific carbohydrate diet.
The present study is still ongoing and we will evaluate vitamin D and folic acid blood levels after 6 months.

To conclude, in our opinion, it is very important to monitor the adherence to the low FODMAP diet during the observational period to evaluate the effective improvement of symptoms and to evaluate the role of other different factors (stress, infections, hormones.) not yet examined.

\section{Conflict of Interests}

None of the authors has any competing interests.

\section{REFERENCE}

1. Longstreth GF, Thompson WG, Chey WD, Houghton LA, Mearin F, Spiller RC. Functional bowel disorders. Gastroenterology 2006; 130: 1480-91

2. Sheperd SJ, Gibson PR. Fructose malabsorption and symptoms of irritable bowel syndrome: guidelines for effective dietary management. J Am diet Assoc 2006; 106:1631-9.

3. Ohman L, Simrén M. New insights into the pathogenesis and pathophysiology of irritable bowel syndrome. Dig Liver Dis 2007; 39: 201-15.

4. Morcos A, Dinan T, Quigley EM. Irritable bowel syndrome: role of food in pathogenesis and management. J Dig Dis 2009; 10:237-46.

5. Dean BB, Aguilar D, Barghout V, Kahler KH, Frech F, Groves D, et al. Impairment in work productivity and helath related quality of life in patients with IBS. Am J manag care 2005; 11 (Suppl): S17-26.

6. Sheperd SJ, Parker FC, Muir JG, Gibson PR. Dietary triggers of abdominal symptoms in patients with irritable bowel syndrome: randomized placebo-controlled evidence. Clin Gastroenterol Hepatol 2008; 6:765-71.

7. Ford AC, Talley NJ, Spiegel BM, Foxx-Orenstein AE, Schiller L, Quigley EM. Effect of fibre, antispasmodics and peppermint oil in the treatment of irritable bowel syndrome. Systematic review and meta-analysis. BMJ 2008; 337: a2313.

8. Luther J, Chey WD. ACP Journal Club. Psyllium increased symptom relief in patients with the irritable bowel syndrome more than bran or placebo. Ann Intern Med 2010; 152: JC1-11.

9. Rees G, Davies J, Thompson R, Parker M, Liepins P. Randomizedcontrolled trial of a fibre supplement on the symptoms of irritable bowel syndrome. J R Soc Health 2005; 125: 30-4.

10. Simrén M, Månsson A, Langkilde AM, Svedlund J, Abrahamsson H, Bengtsson $\mathrm{U}$, et al. Food-related gastrointestinal symptoms in the irritable bowel syndrome. Digestion 2001; 63: 108-15.

11. Niec AM, Frankum B, Talley NJ. Are adverse food reactions linked to irritable bowel syndrome? Am J Gastroenterol 1998; 93: 2184-90.

12. Gibson PR. Food intolerance in functional bowel disorders. J Gastroenterol Hepatol 2011; 26(Suppl 3): S128-31.

13. Barrett JS, Gearry RB, Muir JG, Irving PM, Rose R, Rosella O, et al.

Table 7: Characteristics of the 2 groups at T3

\begin{tabular}{lllll}
\hline & Group A & & Group B & \\
\cline { 2 - 5 } & Female $(n=20)$ & Male $(n=10)$ & Female $(n=18)$ & Male $(n=12)$ \\
\hline Mean BMI $\left(\mathrm{kg} / \mathrm{m}^{2}\right)$ & $24.9 \pm 3.7$ & $25.1 \pm 2.8$ & $24.8 \pm 3.5$ & $29.2 \pm 3.8$ \\
Mean weight $(\mathrm{kg})$ & $64.3 \pm 9.4$ & $71.9 \pm 10.1$ & $64.9 \pm 8.3$ & $81.2 \pm 10.5$ \\
\hline
\end{tabular}


Dietary poorly absorbed, short-chain carbohydrates increase delivery of water and fermentable substrates to the proximal colon. Aliment Pharmacol Ther 2010; 31: 874-82.

14. Berrill JW, Green JT, Hood K, Campbell AK. Symptoms of irritable bowel syndrome in patients with inflammatory bowel disease: examining the role of sub-clinical inflammation and the impact on clinical assessment of disease activity. Aliment Pharmacol Ther 2013; 38: 44-51.

15. El Salhy M, Ostgaard H, Gundersen D, Hatlebakk JG, Hausken T. The role of diet in the pathogenesis and management of irritable bowel syndrome. Int J Mol Med 2012; 29: 723-31.

16. Gibson PR, Shepherd SJ. Personal view: food for thought-Western lifestyle and susceptibility to Crohn's disease. The FODMAP hypothesis. Aliment Pharmacol Ther 2005; 21: 1399-409.

17. Shepherd SJ, Parker SC, Muir JG, Gibson PR. Randomised, placebocontrolled evidence of dietary triggers for abdominal symptoms in patients with irritable bowel syndrome. Clin Gastroenterol Hepatol 2008; 6:765-71.

18. Halmos EP, Power VA, Shepherd SJ, Gibson PR, Muir JG. A diet low in FODMAPs reduces symptoms of irritable bowel syndrome. Gastroenterology 2014; 146: 67-75.e5.

19. Owczarek D, Rodacki T, Domagała-Rodacka R, Cibor D, Mach T. Diet and nutritional factors in inflammatory bowel diseases. World J Gastroenterol 2016; 22: 895-905.

20. Knight-Sepulveda K, Kais S, Santaolalla R, Abreu MT. Diet and Inflammatory Bowel Disease . Gastroenterol Hepatol 2015; 11: 511-20.

21. Obih C, Wahbeh G, Lee D, Braly K, Giefer M, Shaffer ML, et al. Specific carbohydrate diet for pediatric inflammatory bowel disease in clinical practice within an academic IBD center. Nutrition 2016; 32: 418-25.

22. Kakodkar S, Farooqui AJ, Mikolaitis SL, Mutlu EA. The Specific Carbohydrate Diet for Inflammatory Bowel Disease: A Case Series. J Acad Nutr Diet 2015; 115: 1226-32.
23. Nieves R, Jackson RT. Specific carbohydrate diet in treatment of inflammatory bowel disease. Tenn Med 2004; 97: 407.

24. Cohen SA, Gold BD, Oliva S, Lewis J, Stallworth A, Koch B, et al. Clinical and mucosal improvement with specific carbohydrate diet in pediatric Crohn disease. J Pediatr Gastroenterol Nutr 2014; 59: 516-21.

25. Suskind DL, Wahbeh G, Gregory N, Vendettuoli H, Christie D. Nutritional therapy in pediatric Crohn disease: the specific carbohydrate diet. J Pediatr Gastroenterol Nutr 2014; 58: 87-91.

26. Khayyat $Y$, Attar $S$. vitamin D Deficiency in patients with irritable bowel syndrome: does it exist? Oman Med J 2015; 30: 115-8.

27. Bohn L, Storsrud S, Simren M. Nutrient intake in patients with irritable bowel syndrome compared with the general population. Neurogastroenterol Motil 2013; 25: 23-e1.

28. Ford AC, Moayyedi P, Lacy BE, Lembo AJ, Saito YA, Schiller LR, et al. American College of Gastroenterology monograph on the management of irritable bowel syndrome and chronic idiopathic constipation. Am J Gastroenterol 2014; 109(Suppl 1); S2-26; quiz S27.

29. Bijkerk CJ, de Wit NJ, Muris JWM, Whorwell PJ, Knottnerus JA, Hoes AW. Soluble or insoluble fiber in irritable bowel syndrome in primary care? Randomised placebo controlled trial. BMJ 2009; 339: b3154.

30. Moayyedi P, Quigley EM, Lacy BE, Lembo AJ, Saito YA, Schiller LR, et al. The effect dietary intervention on irritable bowel syndrome: a systematic review. Clin Transl Gastroenterol 2015:e107.

31. Austin GL; Dalton CB; Hu Y; Morris CB; Hankins J; Weinland SR, et al. A very low-carbohydrate diet improves symptoms and quality of life in diarrhea-predominant irritable bowel syndrome. Clin Gastroenterol Hepatol 2009; 7: 706-8.

How to cite this article: Vincenzi M, Del Ciondolo I, Pasquini E, Gennai $\mathrm{K}$, Paolini B. Effects of a low FODMAP diet and specific carbohydrate diet on symptoms and nutritional adequacy of patients with irritable bowel syndrome: Preliminary results of a single-blinded randomized trial. J Transl Intern Med 2017; 5: 120-126. 